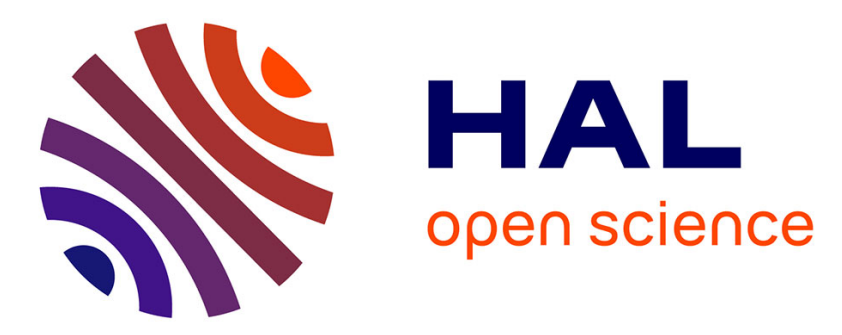

\title{
Experimental investigations of the viscosity of nanofluids at low temperatures
}

Bahadir Aladag, Halelfadl Salma, Nimeti Doner, Thierry Maré, Steven Duret, Patrice Estellé

\section{- To cite this version:}

Bahadir Aladag, Halelfadl Salma, Nimeti Doner, Thierry Maré, Steven Duret, et al.. Experimental investigations of the viscosity of nanofluids at low temperatures. Applied Energy, 2012, 97, pp.876-880. 10.1016/j.apenergy.2011.12.101 . hal-00707410

\section{HAL Id: hal-00707410 https://hal.science/hal-00707410}

Submitted on 28 Jun 2012

HAL is a multi-disciplinary open access archive for the deposit and dissemination of scientific research documents, whether they are published or not. The documents may come from teaching and research institutions in France or abroad, or from public or private research centers.
L'archive ouverte pluridisciplinaire HAL, est destinée au dépôt et à la diffusion de documents scientifiques de niveau recherche, publiés ou non, émanant des établissements d'enseignement et de recherche français ou étrangers, des laboratoires publics ou privés. 


\title{
Experimental investigations of the viscosity of nanofluids at low temperatures
}

\author{
Bahadir Aladag ${ }^{\text {a,c }}$, Salma Halelfadl ${ }^{\text {b,c }}$, Nimeti Doner ${ }^{\text {a }}$, Thierry Maré ${ }^{\text {c }}$, Steven Duret ${ }^{\text {d }}$, \\ Patrice Estellé ${ }^{b, *}$ \\ ${ }^{a}$ Department of Mechanical Engineering, Dumlupinar University, 43270 Kutahya, Turkey \\ ${ }^{\mathrm{b}}$ UEB, LGCGM EA3913, Equipe Matériaux et Thermo-Rhéologie, Insa/Université Rennes 1, \\ IUT de Rennes, 3 rue du Clos Courtel, BP 90422, 35704 Rennes Cedex 7, France \\ c UEB, LGCGM EA3913, Equipe Matériaux et Thermo-Rhéologie, Insa/Université Rennes 1, \\ IUT de Saint-Malo, Rue de la Croix Désilles, CS51713, 35417 Saint-Malo Cedex, France \\ ${ }^{\mathrm{d}}$ Pôle Cristal, Centre Technique Froid et Climatisation, 22100 Dinan, France
}

\author{
* Author to whom correspondence should be addressed. \\ Electronic mail: patrice.estelle@univ-rennes1.fr \\ IUT de Rennes, 3 rue du Clos Courtel, BP 90422, \\ 35704 Rennes Cedex 7, France \\ Tel: $+33(0) 23234200$ \\ Fax: +33(0) 223234051
}

\begin{abstract}
The effects due to temperature and shearing time on viscosity for $\mathrm{Al}_{2} \mathrm{O}_{3}$ /water and $\mathrm{CNT} / \mathrm{water}$ based nanofluids at low concentration and low temperatures are experimentally investigated. The viscosity data were collected using a stress-controlled rheometer equipped with parallel plate geometry under up and down shear stress ramp. CNT and $\mathrm{Al} 2 \mathrm{O} 3$ water based nanofluids exhibited hysteresis behaviour when the stress is gradually loaded and unloaded, depending also on shearing time. Experiments also showed that the nanofluid suspensions indicated either Newtonian or nonNewtonian behaviour, depending on shear rate. CNT water based nanofluid behaves as Newtonian fluid at high shear rate whereas $\mathrm{Al}_{2} \mathrm{O}_{3}$ water based nanofluid is non-Newtonian within the range of low temperatures investigated.
\end{abstract}

Keywords: nanofluid, carbon nanotubes, alumina, viscosity, rheology, hysteresis

\section{Introduction}

In the current context of saving energy, the improvement of the thermal exchanges can be a contribution. In any energetic process, we notice that the energy passes throw, at least once, in heat 
exchanger. The growth of the conditioned air systems also enhances the studies of heat transfer for low temperatures. Nanofluids offer a solution to improve heat exchange. Nanofluids are engineered colloids made of nanoparticles (nanometer-sized particles of metals, oxides, carbides, nitrides or carbon nanotubes...) suspended in a base fluid. During the past decade, many researches are mostly focused on thermal conductivity of nanofluids [1-8]. However, nanofluid's viscosity is as important as thermal conductivity in thermal application involving fluid flow [9]. Actually, viscosity describes the internal resistance of a fluid to flow which is directly related to the pumping power. Mare et al. [10] have studied experimentally the thermal-hydraulic performance of $\mathrm{Al}_{2} \mathrm{O}_{3}$ and carbon nanotubes (CNT) aqueous based nanofluids in a plat heat exchanger at low temperatures. Their results show that the impact of viscosity and pressure drop is important and has to be taking into account before to use nanofluids. Due to high viscosity of $\mathrm{SiO}_{2}$ /water based nanofluids at high particles concentration, Ferrouillat et al. [11] reported that the pumping power is very high and that the practical benefits of using nanofluids is not significant compared to base fluid.

The rheological behaviour of nanofluids could be strongly affected by the preparation method of nanofluids [12], viscosity of the base fluid, particles shape and size [13], particles concentration, temperature, surfactant and dispersion state of the nanoparticles. A number of studies related to the viscosity of nanofluids have been reported.

Chen et al. [14] reported the rheological behavior of $\mathrm{TiO}_{2} /$ Ethylene Glycol nanofluids. Their experimental results show that the $\mathrm{TiO}_{2} / \mathrm{EG}$ nanofluids are Newtonian over a shear rate range of $0.5-10^{4} \mathrm{~s}^{-1}$, the shear viscosity is a strong function of temperature, particle concentration and aggregation and the relative viscosity is independent of the temperature. Later, Chen et al. [15] have investigated the rheological behavior of $\mathrm{TiO}_{2} /$ Ethylene Glycol nanofluids and studied the effects of particles shape, particles concentration and temperature on viscosity. They found that the nanofluids show a shear thinning behavior for the particles concentration above than $2 \%$ and that the temperature imposes a stronger shear thinning. Ngyuen et al. [9] have investigated on particle size effect for $\mathrm{Al}_{2} \mathrm{O}_{3}$ aqueous based nanofluids and observed that the particle size effects on viscosity are more significant for high particles concentration. Numburu et al. [16] studied the rheogical behavior of $\mathrm{SiO}_{2} /$ water and $\mathrm{SiO}_{2} /$ Ethylene Glycol based nanofluids for a range of $-35^{\circ} \mathrm{C}$ to $50^{\circ} \mathrm{C}$. Their results show that the nanofluid is Newtonian for high temperatures and shear thinning for low temperatures. Kulkarni et al [17] studied the effect of temperature for a range from $-35^{\circ} \mathrm{C}$ to $50^{\circ} \mathrm{C}$ for $\mathrm{CuO}, \mathrm{Al}_{2} \mathrm{O}_{3}$ and $\mathrm{SiO}_{2}$ Ethylene Glycol and water based nanofluids. They reported that viscosity decreases exponentially with the increase of temperature. Kole et al. [18] investigated $\mathrm{Al}_{2} \mathrm{O}_{3}$-car engine coolant nanofluid and found that the Brownian motion of the nanoparticles in the fluid plays an important role in understanding the viscosity of nanofluids. 
Paritosh et al. [19] studied the effect of dispersing energy (ultra-sonication) on viscosity of multiwalled aqueous based nanofluids MWCNT. They showed that CNT exhibit a shear thinning behaviour and that the Non-Newtonian character may not be solely attributed to the presence of the surfactant (Gum Arabic). Nguyen et al. [20] have investigated experimentally the effect of the temperature and the particles concentration on viscosity for $\mathrm{Al}_{2} \mathrm{O}_{3}$ aqueous based nanofluids. They showed a hysteresis behavior of dynamic viscosity due to temperature effect, which is more pronounced for high particles concentration. Indeed, they reported that, at any working temperature, the viscosity of the samples during cooling phase is higher than the one measured during the heating of the samples. Many previous results are obtained for temperature ranging from $20^{\circ} \mathrm{C}$ to $60^{\circ} \mathrm{C}$. So, there are few studies done at low temperatures $[10,16]$.

Consequently, the aim of this paper is to investigate the effect of temperature on viscosity of $\mathrm{Al}_{2} \mathrm{O}_{3} /$ water and $\mathrm{CNT} /$ water nanofluids at low concentration and for a range of temperatures from $2^{\circ} \mathrm{C}$ to $10^{\circ} \mathrm{C}$. One highlight of this work is that the viscosity hysteresis phenomenon is here observed when the stress is gradually loaded and unloaded, as shown in section 3. In this section, the rheological behavior of the nanofluids are also described and discussed in terms of shear rate and temperature effect. We finally summarize in section 4 the main conclusions reported so far.

\section{Viscosity}

Some theoretical formulas have been proposed to relate the viscosity of colloidal suspensions or nanofluids to particle volume fraction. They derived from the pioneering model of Einstein [21]. This model is based on the assumption of viscous fluid containing non-interacting rigid spherical particles under low particle volume fraction, typically less than $1 \%$.

$$
\mu_{n f}=\mu_{b f}(1+2.5 \phi)
$$

where $\mu_{\mathrm{nf}}$, and $\mu_{\mathrm{bf}}$ indicate the viscosity of the nanofluid and the base fluid respectively, and $\phi$ is the volume fraction of nanoparticle in base fluid.

Later, Brinkman [22] presented a viscosity correlation that extended Einstein's equation to suspensions with moderate particle volume fraction, typically less than $4 \%$. 


$$
\mu_{n f}=\mu_{b f} \frac{1}{(1-\phi)^{2.5}}
$$

Batchelor [23] proposed the following equation considering the Brownian motion of nanoparticles and their interaction, as given by equation (3).

$$
\mu_{n f}=\mu_{b f}\left(1+\eta \phi+k_{H} \phi^{2}+\ldots\right)
$$

In this equation, $\eta$ is the intrinsic viscosity and $k_{H}$ is Huggins' coefficient. The value of $\eta$ and $k_{H}$ is 2.5 , respectively 6.5 , for spherical particles.

If particles are non-spherical, Brenner and Condiff [24] have developed a viscosity model to consider the shape effects. So, for rod like particles, the Brenner and Condiff equation is applicable for volume fraction up to $1 / \mathrm{r}^{2}$, where $\mathrm{r}$ is the aspect ratio of nanoparticles.

$$
\mu_{n f}=\mu_{b f}(1+\eta \phi)
$$

With

$$
\eta=\frac{0.312 r}{\ln 2 r-1.5}+2-\frac{0.5}{\ln 2 r-1.5}-\frac{1.872}{r}
$$

It is worth noting that the previous equations were developed to relative viscosity as a function of particle volume fraction only. There is no consideration of temperature dependence. Moreover, these equations are for homogenous fluid and do not take into account particle agglomeration influence.

\section{Materials and experiments}

\subsection{Nanofluids}

The first nanofluid is supplied by Nissan Chemical. The material is a suspension of alumina nanospheres of $30 \mathrm{~nm}$ in diameter dispersed in a mixture of water and a surfactant. Its $\mathrm{pH}$ is 5 and the weight fraction of nanoparticles is $1 \%$. The second nanofluid is supplied by Nanocyl (Belgium) and consists in multi-walled carbon nanotubes (carbon purity 90\%) dispersed in a similar mixture. The dimensions of the nanotubes are $200 \mu \mathrm{m}$ in length and $9 \mu \mathrm{m}$ in average diameter respectively according to the manufacturer's specification. . This leads to an aspect ratio of $r=L / d \approx 22$. The weight fraction of nanotubes is also $1 \%$. Each nanofluid contains $1 \%$ by volume of surfactant but its 
nature is not released by the suppliers of nanofluids. The role of surfactant is to disperse and stabilize the particles and reduce the presence of aggregates, as well as to adjust the $\mathrm{pH}$ of the nanosuspension. It is expected that the influence of the surfactant in terms of density and heat capacity of nanofluids is low. On the other hand we believe that the nature and the quantity of surfactant play a role in the viscosity of nanofluids, as recently shown by Phuoc et al. [25] for multi-wall carbon nanotubes suspension stabilized by chitosan. However, this is below the scope of the present work.

It was shown that characterization of the nanofluid suspension can be performed by particle size analyzer based on dynamic light scattering. Dynamic light scattering measurement was previously performed on the CNT nanofluid investigated in this study [10]. This technique was reported to be effective in indicating the presence of agglomerates [26]. However such a measurement assumed spherical particles resulting in an average value for the length of the particles [27]. It was reported in [10] that the measured average particle size in the CNT nanofluids is much larger than that of the primary nanoparticles suggesting the nanotubes to form clusters in spite of the use of surfactant. The average agglomerate sizes for the CNT water based nanofluid is $380 \mathrm{~nm}$. A similar result was observed for $\mathrm{Al}_{2} \mathrm{O}_{3}$ water based nanofluid under lower concentration than that of the present work.

\subsection{Experiments}

The rheological properties of both nanofluids were measured by a stress controlled rheometer (Malvern Kinexus Pro) in a parallel plate configuration under controlled temperature. The diameter of the plates is $40 \mathrm{~mm}$ and the gap is $0.5 \mathrm{~mm}$. The temperature was controlled by using a peltier temperature control device located below the lower plate with an accuracy of $0.01^{\circ} \mathrm{C}$. Thermal clovers were also used to ensure constant temperature within the sample gap. Each tested volume sample was taken from its container then set up to the lower plate, taking care that no air bubbles were entrapped within the sample. Hence, the upper plate is displaced to achieve the required sample gap. The excess of samples is eventually removed. Unlike most studies done in the literature, where the rheological behaviour of nanofluids is only measured under increasing shear rate (or shear stress), the measurements were here performed in imposing an up and down ramp in shear stress. So, the stress is gradually loaded logarithmically then followed by a reverse stress decrease. During the experiments, we measured the instantaneous shear rate and apparent viscosity and did not necessarily reach a steady state during experiments. The range of the up and down stress ramp varies between $10^{-1}$ and $15 \mathrm{~Pa}$, respectively $10^{-1}$ and $30 \mathrm{~Pa}$, for the $\mathrm{Al}_{2} \mathrm{O}_{3}$ nanofluid and the CNT nanofluid. Preliminary measurements have validated the applicability of the maximum shear stress (15 and $30 \mathrm{~Pa}$ ) depending on the nanofluid used, in order to avoid flow instability, 
sample ejection and ensure a constant normal force during experiments. The torque resolution of the rheometer is $0.1 \mathrm{nNm}$. As a consequence, the uncertainty in shear stress under the parallel plate geometry used is $1.210^{-6} \mathrm{~Pa}$. The angular velocity resolution is at least $10 \mathrm{nrad} / \mathrm{s}$. The uncertainty in shear rate, which only depends on angular velocity under parallel plate geometry as the normal force is maintained constant during test, is less than $10^{-5} \mathrm{~s}^{-1}$.

The working temperatures were $2^{\circ} \mathrm{C}, 5^{\circ} \mathrm{C}, 7^{\circ} \mathrm{C}$ and $10^{\circ} \mathrm{C}$, and the time of shear stress ramp were $120 \mathrm{~s}, 180 \mathrm{~s}, 240 \mathrm{~s}$ and $300 \mathrm{~s}$. This is made for both investigating the influence of low temperature and shearing time on the rheological properties of the nanofluids. It should be mentioned that the measurements were performed on the same sample for a decrease or an increase of the working temperatures, which was maintained 5 minutes before starting the experiment. It is also mentioned that no high preshear mixing neither sonification were used before testing the nanofluids. In addition, any observable sedimentation was noticed before experiments.

The experiments were also repeated at least once to verify the repeatability of the rheological measurement. This was also done to evaluate the suspensions stability with time. As reported, particle size analyzer accounts for nanoparticles agglomeration but it does not provide the insight required on the nanofluid colloidal stability.

Figure 1 shows the relationship between the shear stress and shear rate for the studied CNT water based nanofluid at $7^{\circ} \mathrm{C}$ for two replicates under a shearing time of $300 \mathrm{~s}$. As reported in figure 1, the different shear flow curves are well superimposed within the shear stress range investigated, indicating that the nanofluid was stable during the experimental work. Similar results were obtained for other temperatures, shearing times and the $\mathrm{Al}_{2} \mathrm{O}_{3}$ /water nanofluid. So, in the following, the shear flow curves and the rheological parameters are average values of the different experiments.

\section{Results and discussion}

\subsection{Influence of shearing time}

Figures 2 and 3 respectively show the shear stress versus shear rate curves of the CNT nanofluid and the $\mathrm{Al}_{2} \mathrm{O}_{3}$ nanofluid at $5^{\circ} \mathrm{C}$ obtained from different shearing times, under increasing and decreasing ramp in shear stress. It should be mentioned that, in both figures, the shear flow curve under increasing ramp in shear stress is greater than the one obtained under decreasing ramp in shear stress.

So, figures 2 and 3 describe apparent hysteresis loops which are generally obtained with thixotropic materials [28], defined as time-dependant structurated materials. Figures 2 and 3 also show that the area and the shape of the hysteresis loop vary according to the nanofluid and the shearing time. This can be explained from the basis of nanofluid microstructure and attractive force between the 
particles. Nanofluids are well known as structured materials with particles or aggregates, even at low concentration. So, during the increasing ramp in shear stress, the structure and the flocculants of the nanofluid break down and decrease further when the shear stress is increased. Inversely, during reverse phase, reducing the stress rate can cause a growth of the flocculants and/or allow the particulate network to rebuild. So, increasing the shearing time allow the material to rebuild and retrieve an initial structure. The rebuild of initial structure is influenced by shearing time rather than shear rate. This phenomenon is less pronounced for the CNT nanofluid, as the hysteresis loop is quite identical for the three shearing times used. So, here the destruction and re-build of nanosuspension structure is only shear dependant. The behaviour described in figure 2 and 3 may be explained, at least in part, in terms of the time dependency of agglomeration and desagglomeration kinetics linked to the structural network of the nanofluids.

We can also see at low shear rate under the up shear stress ramp than the shear stress versus shear rate curves are not superimposed. This can be explained by the initial state of the material before experiment as no preshear was applied to the sample before testing. It should be mentioned than the results presented here for a temperature of $5^{\circ} \mathrm{C}$ are similar to ones obtained with the other temperatures (see figure 1 as example). Finally, figures 2 and 3 show that the CNT nanofluid and the $\mathrm{Al}_{2} \mathrm{O}_{3}$ nanofluid seems to behave as non-newtonian materials, as it will be discussed in section 3.2. In the following experimental data, we have considered the case of decreasing ramp in shear stress which provide the shear flow behaviour of nanofluids after the breaking of their structural network under increasing ramp. In order to compare the rheological properties of the water based nanofluids under low temperatures, the same shearing time of 240 s was also considered.

\subsection{Rheological properties of nanofluids: Influence of shear rate and temperature}

Figure 4 reports the evolution of the apparent viscosity depending of shear rate for the different temperatures of CNT nanofluid. First at all, it is observed that the shear flow behaviour of CNT nanofluid is obtained within a large shear rate range.

Figures 4 shows that the CNT suspension behaves as a non-newtonian shear thinning fluid under the experimental conditions of this work, as the apparent viscosity of the CNT suspension decreases when the shear rate increases. Figure 4 also shows that the apparent viscosity decreases as the temperature increases, as mainly reported for a wide class of nanofluids. As shown in Figure 4, the shear viscosity of the CNT suspension mainly decreases for a shear rate lower than $100 \mathrm{~s}-{ }^{1}$. Over this shear rate value, the apparent shear viscosity tends to a Newtonian plateau. This is in agreement with the measurements of Kanagaraj et al. [29] who have investigated the rheological behaviour of CNT nanofluid under the same weigh fraction that of the present work and for temperature ranging from $20^{\circ} \mathrm{C}$ to $50^{\circ} \mathrm{C}$. As mainly reported, shear thinning effect can be attributed to de-agglomeration 
of the nanotube clusters and/or realignment of the clusters in the direction of the shearing flow due to the form of primary particles, resulting in less viscous force. The fact that CNT nanofluids are mainly treated as Newtonian fluid may be plausible following the shear rate range investigated. So, from the previous figure and results, the CNT nanofluid can be considered as a Newtonian fluid for high shear rate. In, this case we can obtain the dynamic viscosity of the nanofluid from the following relationship.

$$
\tau=\mu \dot{\gamma}
$$

Where $\tau$ is the shear stress, $\mu$ is viscosity and $\dot{\gamma}$ is the shear rate. Figure 5 shows the evolution of viscosity of CNT nanofluid with temperature as well as the comparison with the Brinkman formula (see eq.2). The Brenner and Condiff equation was not considered here as the volume fraction of CNT nanofluid, which is $0.55 \%$, is up to $1 / \mathrm{r}^{2}=0.2 \%$. It is shown that the viscosity of CNT suspension decreases about $26 \%$ when the temperature increases from 2 to $10^{\circ} \mathrm{C}$.

Figure 5 indicates also that the viscosity values of CNT suspension are five times higher than the ones predicted by the Brinkman equation. These results show that Brinkman's formula seems to be not efficient for the CNT nanofluid investigated here due to the presence of aggregates.

Figure 6 reports the evolution of shear stress of $\mathrm{Al}_{2} \mathrm{O}_{3}$ nanofluid depending of shear rate and for the different tested temperatures. Figure 6 shows that the $\mathrm{Al}_{2} \mathrm{O}_{3}$ nanofluid behaves as a non-Newtonian shear-thickening fluid under the experimental conditions of this work within a large shear rate range.

From the experimental data, a correlation between shear stress and shear rate can be obtained from the non-Newtonian power law model, defined by equation (7), in order to find out the characteristic flow behaviour of $\mathrm{Al}_{2} \mathrm{O}_{3}$ aqueous suspension with temperature.

$$
\tau=K \dot{\gamma}^{n}
$$

where $\tau$ is the shear stress in $\mathrm{Pa}, \mathrm{n}$ is the flow behaviour index, $\mathrm{K}$ is the flow consistency index in Pa.s ${ }^{\mathrm{n}}$ and $\dot{\gamma}$ is the shear rate in $\mathrm{s}^{-1}$.

The shear thickening effect may be related to a transition of suspension structure from an ordered state to a rather disordered state. Increasing the shear stress is so that the particles or clusters are displaced from their equilibrium position to become a disorder structure which dissipates more energy during flow leading to the increase of the mixture viscosity. Shear thickening of $\mathrm{Al}_{2} \mathrm{O}_{3}$ aqueous nanofluid was also observed in [30]. 
Fitting equation (7) to the shear stress versus shear rate curves allows determining the power law model parameters of the $\mathrm{Al}_{2} \mathrm{O}_{3}$ nanofluid against temperature. This is reported in figure 7 . The $\mathrm{R}^{2}$ correlation coefficient for each of the curve of figure 6 was found to be more than 0.99 , indicating a good correlation. Figure 7 shows that, for $\mathrm{Al}_{2} \mathrm{O}_{3}$ nanofluids, the temperature increase induces a diminution of the consistency index, and an increase of the flow index. It is also noted that the effect of temperature in the reduction in consistency index is about $57 \%$ when the temperature increases from 2 to $10^{\circ} \mathrm{C}$. When the temperature increases it is also shown that the flow behaviour index of $\mathrm{Al}_{2} \mathrm{O}_{3}$ increases about $5.57 \%$.

The difference in non-Newtonian behaviour of $\mathrm{Al}_{2} \mathrm{O}_{3}$ and $\mathrm{CNT}$ nanofluids could be attributed, at least partially to different particle shape and aspect ratio, agglomeration and desagglomeration kinetics due to the interaction between the surfactant and the nanoparticles.

\section{Conclusion}

In this paper, we have established a new and more complete viscosity data base for two particular water-based nanofluids, namely $\mathrm{Al}_{2} \mathrm{O}_{3}$-water and CNT-water, at low concentration. The effects due to temperature and shearing time on the rheological properties of nanofluids were investigated for low temperatures ranging from $2{ }^{\circ} \mathrm{C}$ to $10^{\circ} \mathrm{C}$. Experimental data have clearly revealed for both nanofluids that a viscosity hysteresis phenomenon is observed when the stress is gradually loaded and unloaded, a thixotropic shear time dependent phenomenon. This hysteresis phenomenon, which is believed to be the first observed for $\mathrm{Al}_{2} \mathrm{O}_{3}$-water and CNT-water based nanofluids, has raised a lot of interest regarding the use of nanofluids for heat transfer enhancement purposes. Experimental results showed that the nanofluids have different rheological behaviors. Alumina water based nanofluid is non-Newtonian and CNT water based nanofluid is Newtonian only for high shear rate. In this complex problem of nanofluid rheology, we have to take into account agglomeration phenomenon, surfactant impact, and shape influence to better understand the flow properties of such fluids. This is the objective of future works.

\section{Acknowledgments}

Nanocycl Belgium is gratefully acknowledged for the preparation of CNT water based nanofluid.

The Pôle Cristal of Dinan that has contributed to this study is also gratefully acknowledged. 


\section{References}

[1] Daungthongsuk W, Wongwises S. A critical review of convective heat transfer of nanofluids. Ren Sust Energy Rev 2007;11:797-817.

[2] Maïga SEB, Palm SJ, Nguyen CT, Roy G, Galanis N. Heat transfer enhancement by using nanofluids in forced convection flows. Int J Heat Fluid Flow 2005;26:530-546.

[3] Maïga SEB, Nguyen CT, Galanis N, Roy G, Maré T, Coqueux M. Heat transfer enhancement in turbulent tube flow using $\mathrm{Al}_{2} \mathrm{O}_{3}$ nanoparticle suspension. Int $\mathrm{J}$ Numer Math Heat Fluid Flow 2006;16:275-292.

[4] Thomas S, Sobhan CBP. A review of experimental investigations on thermal phenomena in nanofluids. Nano Res Lett 2011;6:377.

[5] Assael MJ, Metaxa IN, Arvanitidis J, Christophilos D, Lioutas C. Thermal conductivity enhancement in aqueous suspensions of carbon multi-Walled and double-walled nanotubes in the presence of two different dispersants. Int J Thermophysics 2005;26:647-664.

[6] Liu MS, Lin MCC, Haung IT, Wang CC. Enhancement of thermal conductivity with carbon nanotube for nanofluids. Int Commun Heat Mass Transfer 2005;32:1202-1210.

[7] Li $\mathrm{CH}$, Peterson GP. Experimental investigation of temperature and volume fraction variations on the effective thermal conductivity of nanoparticle suspensions (nanofluids). J Appl Phys 2006;99:084314.

[8] Lin C-Y, Wang J-C, Chen T-C. Analysis of suspension and heat transfer characteristics of A12O3 nanofluids prepared through ultrasonic vibration. App Energy 2011;88:4527-4533.

[9] Nguyen CT, Desgranges F, Roy G, Galanis N, Maré T. Temperature and particles-size dependent viscosity data for water-based nanofluids -Hysteresis phenomenon. Int $\mathbf{J}$ Heat Fluid Flow. 2007;28:1492-1506.

[10] Maré T, Halelfadl S, Sow O, Estellé P, Duret S, Bazantay F. Comparison of the thermal performances of three nanofluids at low temperature in a plate heat exchanger. Exp Thermal Fluid Sci. 2011;35:1535-1543.

[11] Ferrouillat S, Bontemps A, Ribeiro JP, Gruss JA, Soriano O. Hydraulic and heat transfer study of $\mathrm{SiO}_{2}$ /water nanofluids in horizontal tubes with imposed wall temperature boundry conditions. Int J Heat Fluid Flow 2011;32:424-439.

[12] Wang X, Choi SUS. Thermal conductivity of nanoparticle-fluid mixture. J Thermophys Heat Transfer 1999;13:474-480.

[13] Chevalier J, Tillement O, Ayela F. Rheogical Properties of nanofluids flowing through microchannels. Appl Phys Lett 2007;91:233103.

[14] Chen HS, Ding YL, Tan CQ. Rheological behaviour of nanofluids. New J Phys 2007;9:1-25.

[15] Chen HS, Ding YL, Lapkin A, Fan X. Rheological behaviour of ethylene glycol-titanate nanotube nanofluids. J Nanopart Res 2009;11:1513-1520. 
[16] Numburu PK, Kulkarni DP, Dandekar A, Das DK. Experimental investigation of viscosity and specific heat of silicon dioxide nanofluids. Micro Nano Lett 2007;2:67-71.

[17] Kulkarni DP, Debendra KD, Ravikanth SV. Application of nanofluids in heating buildings and reducing pollution. App Energy 2009;86:2566-2573.

[18] Kole M, Dey TK. Thermal conductivity and viscosity of Al2O3 nanofluid based on car engine coolant. J Phys D Appl Phys 2010;43:315501.

[19] Paritosh G, Jorge LA, Marsh C, Carlson TA, Kessler DA, Annamalai K. An experimental study on the effect of ultrasonication on viscosity and heat transfer performance of multi-wall carbon nanotube-based aqueous nanofluids. Int Journal Heat Mass Transfer 2009;52:5090-5101.

[20] Nguyen CT, Desgranges F, Roy G, Galanis N, Maré T, Butcher S, Mintsa HA. Viscosity data for $\mathrm{Al}_{2} \mathrm{O}_{3}$-water nanofluids- hysteresis: is heat transfer enhancement using nanofluids reliable?, Int J Thermal Sci 2008;47:103-111.

[21] Einstein A. Investigations on the Theory of the Brownian Movement. Dover Publications, Inc., New York (1956).

[22] Brinkman HC. The viscosity of concentrated suspensions and solutions. J Chem Phys 1952;20:571-581.

[23] Batchelor G. The effect of Brownian motion on the bulk stress in a suspension of spherical particles. J Fluid Mech 1977;83:97-117.

[24] Brenner H, Condiff DW. Transport mechanics in systems of orientable particles. Part IV. Convective transport. J Colloid Interface Sci 1974;47:199-264.

[25] Phuoc TX, Massoudi M, Chen RH. Viscosity and thermal conductivity of nanofluids containing multi-walled carbon nanotubes stabilized by chitosan. Int J Ther Sci 2011;50:12-18.

[26] Vaisman L, Marom G, Wagner HD. Dispersions of surface-modified carbon nanotubes in water-soluble and water-insoluble polymers. Adv Funct Mater 2006;16:357-363.

[27] Vaisman L, Wagner HD, Marom G. The role of surfactants in dispersion of carbon nanotubes. Adv Coll Int Sci 2006;128-130:37-46.

[28] Mewis J, Wagner NJ. Thixotropy, Adv Colloid Interface Sci 2009;147-148:214-227.

[29] Kanagaraj S, Varabda FR, Fonseca A, Ponmozhi J, Lopez da Silva JA, Oliveira MSA et al. Rheological study of nanofluids at different concentration of carbon nanotubes, 19th National \& 8th ISHMT-ASME Heat Mass Transfer Conf, January 3-5, 2008 hvderabad, India (paper NFF-7).

[30] Tseng WJ, Wu CH. Aggregation, rheology and electrophoretic packin structure of aqueous $\mathrm{Al}_{2} \mathrm{O}_{3}$ nanoparticle suspensions. Acta Mat 2002;50:3757-3766. 


\section{Highlights}

- Experimental viscosity of two nanofluids $\left(\mathrm{Al}_{2} \mathrm{O}_{3} ; \mathrm{CNTs}\right)$ at low temperatures

- Viscosity hysteresis phenomenon showing thixotropy

- Shearing time influence

- Non-Newtonian behaviour of $\mathrm{Al}_{2} \mathrm{O}_{3}$ water nanofluid

- Newtonian behaviour of CNT water based nanofluid at high shear rate. 


\section{Figure Captions}

Figure 1. Shear stress versus shear rate of CNT nanofluid at $7^{\circ} \mathrm{C}$ for a shearing time of $300 \mathrm{~s}-$ evaluation of repeatability of the tests and stability of the nanofluid.

Figure 2. Shear stress versus shear rate of CNT nanofluid at $5^{\circ} \mathrm{C}-$ influence of shearing time.

Figure 3. Shear stress versus shear rate of $\mathrm{Al}_{2} \mathrm{O}_{3}$ nanofluid at $5^{\circ} \mathrm{C}$ - influence of shearing time.

Figure 4. Apparent viscosity versus shear rate of CNT nanofluid - influence of temperature.

Figure 5. Viscosity of CNT suspension.

Figure 6. Shear stress versus shear rate of $\mathrm{Al}_{2} \mathrm{O}_{3}$ nanofluid - influence of temperature.

Figure 7. Evolution of power law parameters, fitted to shear stress versus shear rate curves of $\mathrm{Al}_{2} \mathrm{O}_{3}$ nanofluid, against temperature. 


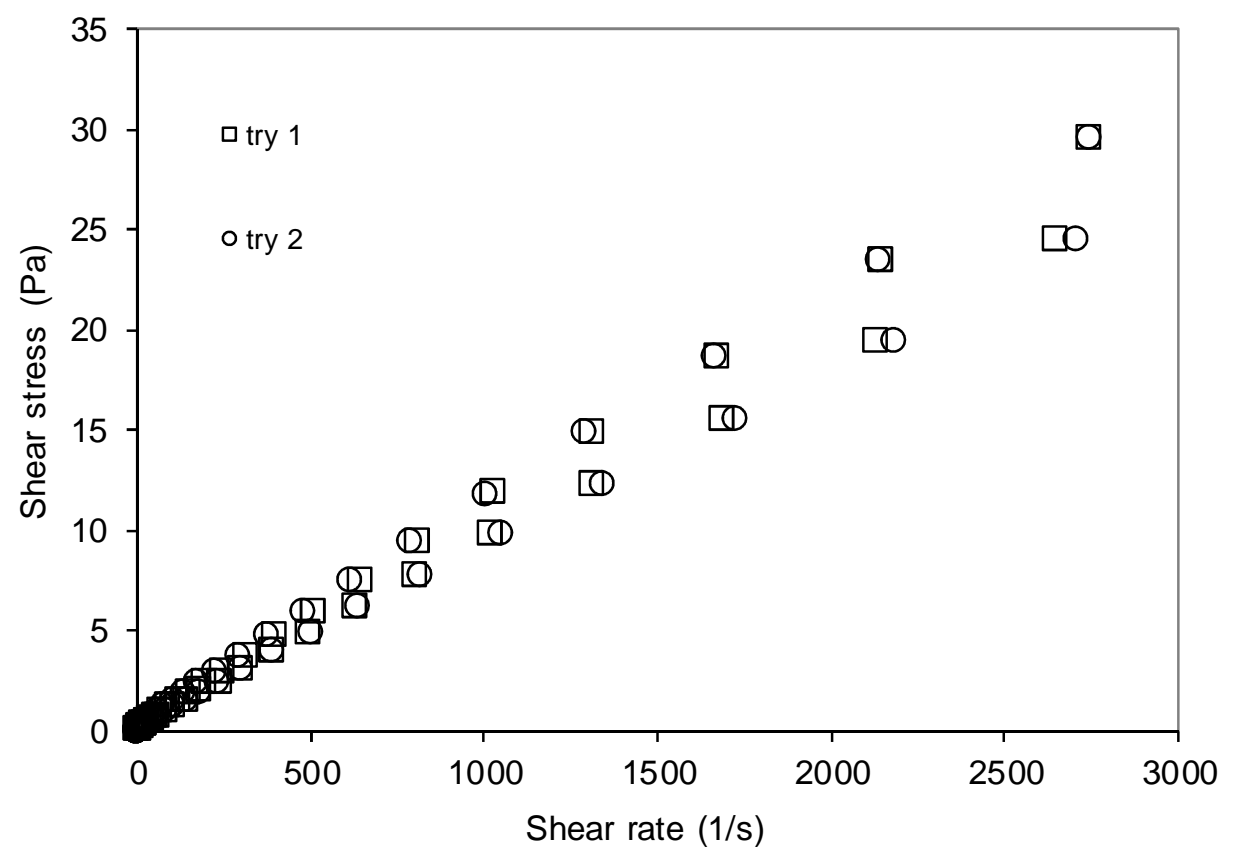

Figure 1. Shear stress versus shear rate of CNT nanofluid at $7^{\circ} \mathrm{C}$ for a shearing time of $300 \mathrm{~s}-$ evaluation of repeatability of the tests and stability of the nanofluid.. 


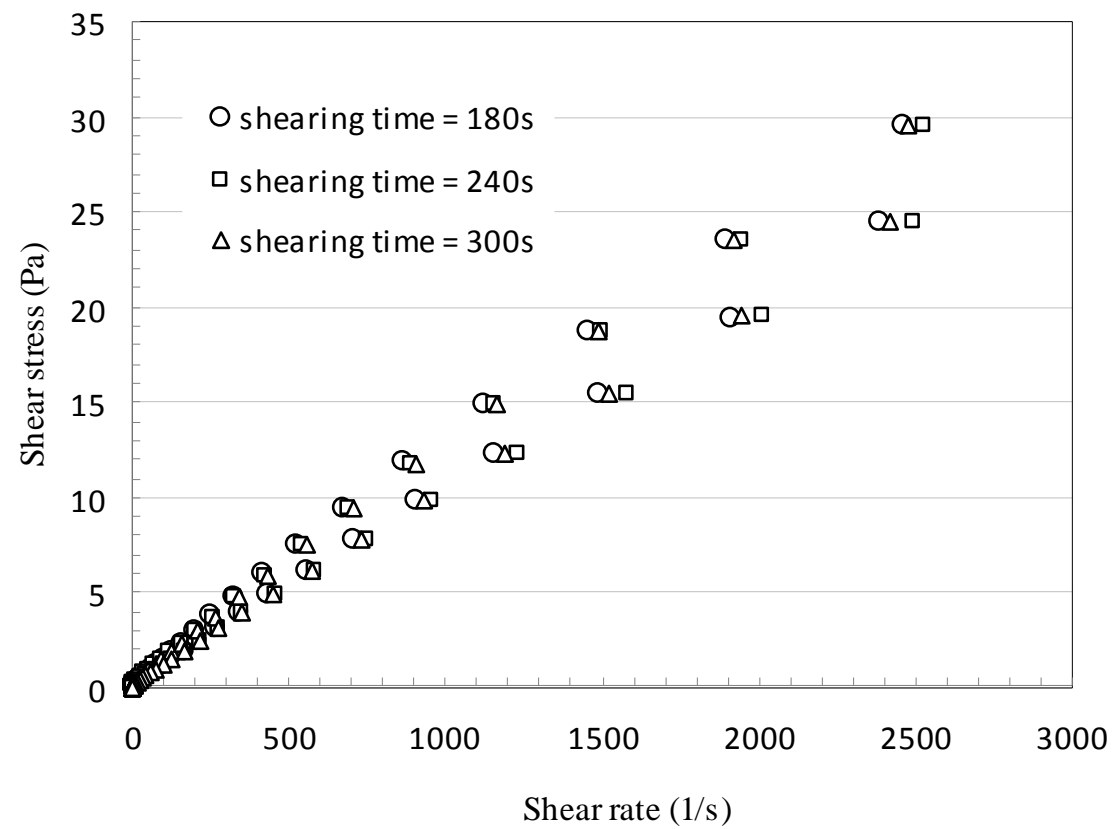

Figure 2. Shear stress versus shear rate of CNT nanofluid at $5^{\circ} \mathrm{C}-$ influence of shearing time. 


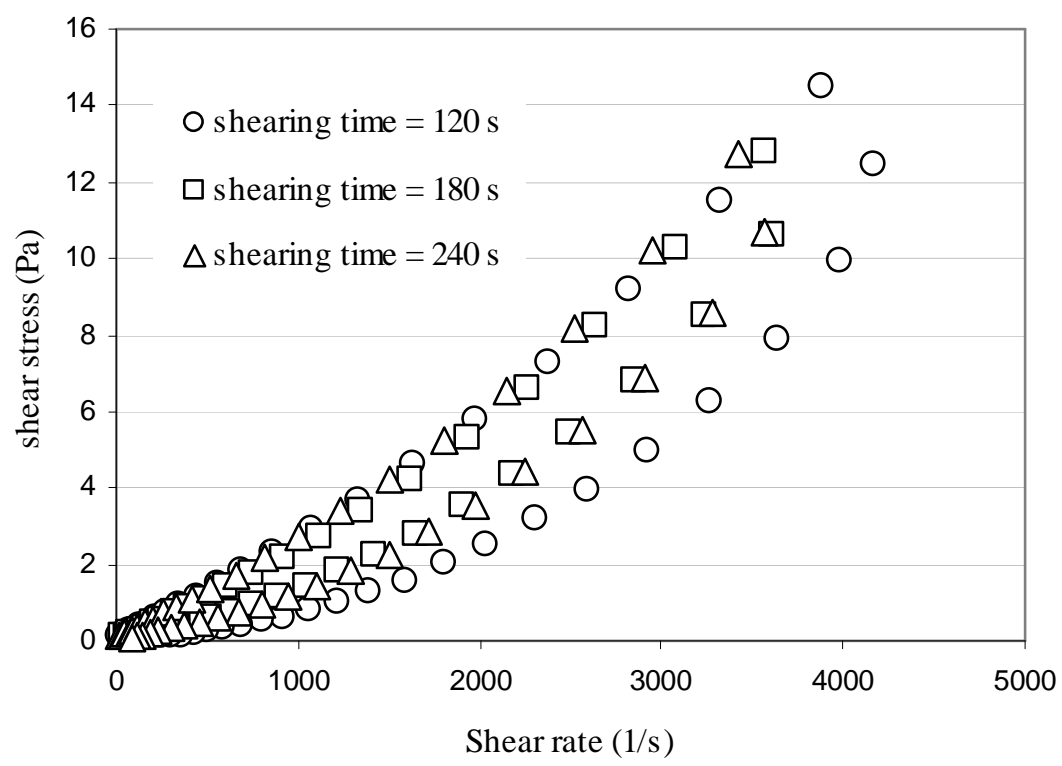

Figure 3. Shear stress versus shear rate of $\mathrm{Al}_{2} \mathrm{O}_{3}$ nanofluid at $5^{\circ} \mathrm{C}$ - influence of shearing time. 


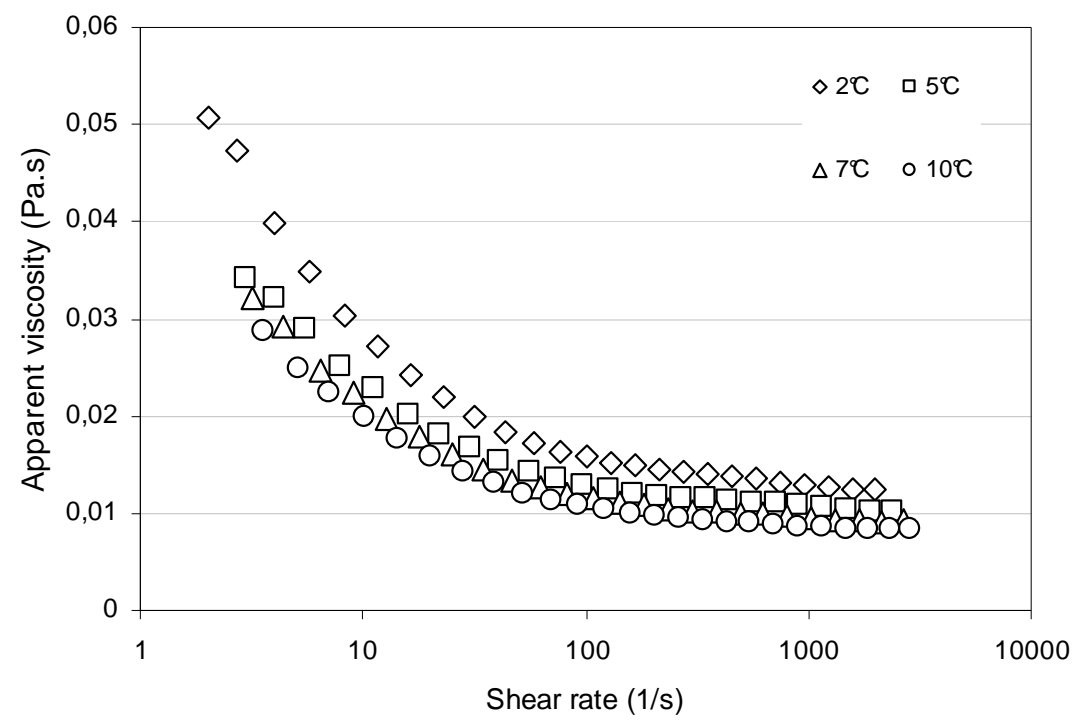

Figure 4. Apparent viscosity versus shear rate of CNT nanofluid - influence of temperature. 


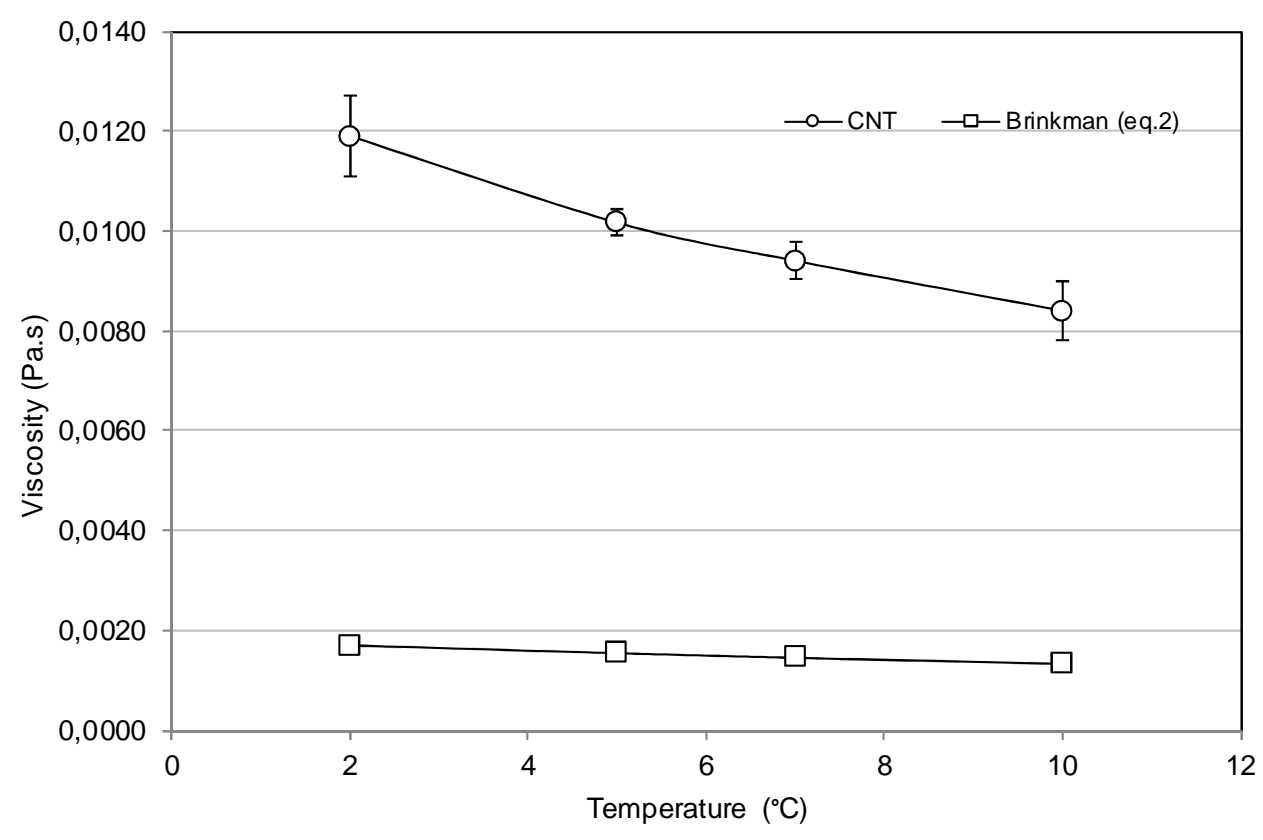

Figure 5. Viscosity of CNT suspension against temperature. 


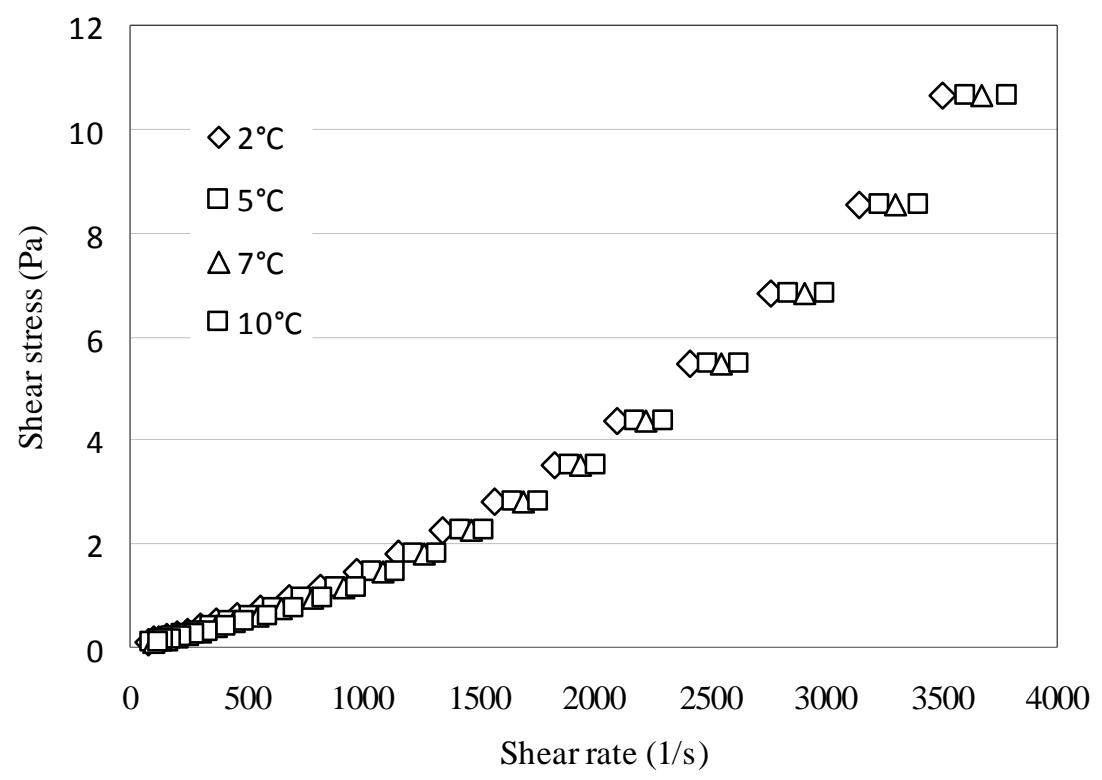

Figure 6: shear stress versus shear rate of $\mathrm{Al}_{2} \mathrm{O}_{3}$ nanofluid - influence of temperature. 


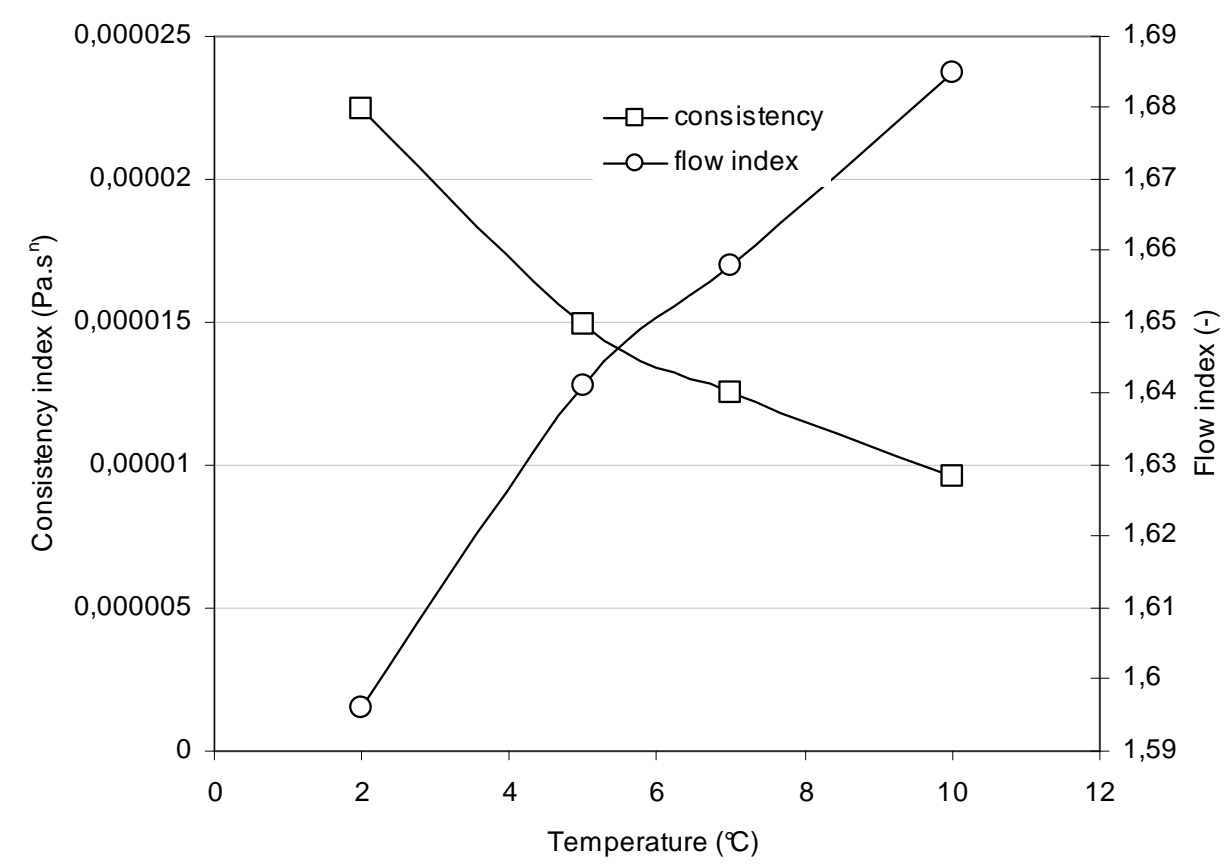

Figure 7. Evolution of power law parameters, fitted to shear stress versus shear rate curves of $\mathrm{Al}_{2} \mathrm{O}_{3}$ nanofluid, against temperature. 